Original Research Paper

\title{
Dynamics of Buses - Part III
}

\author{
${ }^{1}$ Relly Victoria Virgil Petrescu, ${ }^{2}$ Raffaella Aversa, ${ }^{1}$ Gheorghe Frățilă, \\ ${ }^{3}$ Taher M. Abu-Lebdeh, ${ }^{2}$ Antonio Apicella and ${ }^{1}$ Florian Ion Tiberiu Petrescu \\ ${ }^{1}$ ARoTMM-IFToMM, Bucharest Polytechnic University, Bucharest, (CE), Romania \\ ${ }^{2}$ Department of Architecture and Industrial Design, Advanced Material Lab, \\ Second University of Naples, 81031 Aversa (CE), Italy \\ ${ }^{3}$ North Carolina A and T State University, USA
}

Article history

Received: 02-03-2018

Revised: 02-04-2018

Accepted: 18-04-2018

Corresponding Author: Florian Ion Tiberiu Petrescu ARoTMM-IFToMM, Bucharest Polytechnic University, Bucharest, (CE), Romania

Email: scipub02@gmail.com

\begin{abstract}
Dynamics, or dynamic processes, is the part of mechanics dealing with the study of processes trying to describe as real as possible the movement of a body, element, mechanism, car, etc., also taking into account the action of the forces on the respective system with their influence on the actual movement of system. The present paper aims to present the study of the dynamics of the vehicles, with particularization on the buses. Here are the main elements of the bus dynamics, taking into account all the elements that influence the dynamic operation of a bus, in general and in particular situations, with emphasis on the main systems and elements that act on the actual, dynamic, on a normal path or on an inclined with an alpha angle path. The position of the bus center on a bus needs to be known first in order to study the stability of the bus and then to determine the normal dynamic reactions for the suspension design... The position of the center of mass in the longitudinal plane is determined by weighing the bus on a tiller. In the beginning determine the maximum total mass of the $G_{t}$ bus and then two other weights determine the loads $G_{1}$ and $G_{2}$ that belong to the front and to the rear axle. The stability of the bus will be studied, which means its ability not to overturn or slip during travel or in stationary. The longitudinal stability of the bus means its ability not to overturn around the rear or front wheels or to slip longitudinally when climbing a slope. Figure 3 considers a bus that climbs a slope at a low and uniform speed. The movement can be considered because the overturning can occur in the case of large slopes. Flipping around the straight line through the contact points B of the rear wheels with the road may occur when the tipping moment is greater than the moment of stability relative to the same point, i.e.
\end{abstract}

Keywords: Mechanisms, Machines, Buses, Dynamics, Kinematics

\section{Introduction}

Transport management is the responsibility of transport engineering and engineering for the design of transport networks and systems, aiming at optimizing transport systems, increasing transport safety, protecting the environment, etc.

The most widespread and efficient form of land transport uses vehicles equipped with liquid-fueled engines (Frăţilă et al., 2011; Pelecudi, 1967; Antonescu, 2000; Comănescu et al., 2010; Aversa et al., 2016a; 2016b; 2016c; 2016d; 2017a; 2017b; 2017c; 2017d; 2017e; Mirsayar et al., 2017; Cao et al., 2013; Dong et al., 2013; De Melo et al., 2012; Garcia et al., 2007; Garcia-
Murillo et al., 2013; He et al., 2013; Lee, 2013; Lin et al., 2013; Liu et al., 2013; Padula and Perdereau, 2013; Perumaal and Jawahar, 2013; Petrescu and Petrescu, $1995 \mathrm{a} ; 1995 \mathrm{~b} ; 1997 \mathrm{a} ; 1997 \mathrm{~b} ; 1997 \mathrm{c} ; 2000 \mathrm{a} ; 2000 \mathrm{~b}$; 2002a; 2002b; 2003; 2005a; 2005b; 2005c; 2005d; 2005e, 2016a; 2016b; 2016c; 2016d; 2016e; 2013; 2012a; 2012b; 2011; Petrescu et al., 2009; 2016a; 2016b; 2016c; 2016d; 2016e; 2017a; 2017b; 2017c; 2017d; 2017e; 2017f; 2017g; 2017h; 2017i; 2017j; 2017k; 2017l; 2017m; 2017n; 2017o; 2017p; 2017q; 2017r; 2017s; 2017t; 2017u; 2017v; 2017w; 2017x; 2017y; 2017z; 2017aa; 2017ab; 2017ac; 2017ad; 2017ae; Petrescu and Calautit, 2016a; 2016b; Reddy et al., 2012; Tabaković et al., 2013; Tang et al., 2013; Tong et al., 2013; Wang et al., 2013; Wen et al., 2012; Antonescu and
Science

Publications 
Petrescu, 1985; 1989; Antonescu et al., 1985a; 1985b; 1986; 1987; 1988; 1994; 1997; 2000a; 2000b; 2001).

\section{Materials and Methods}

\section{The Bus Mass Center}

The position of the bus center on a bus needs to be known first in order to study the stability of the bus and then to determine the normal dynamic reactions for the suspension design...

The position of the center of mass in the longitudinal plane is determined by weighing the bus on a tiller. In the beginning determine the maximum total mass of the $G_{t}$ bus and then two other weights determine the loads $G_{1}$ and $G_{2}$ that belong to the front and to the rear axle (Fig. 1).

Knowing the loads $G_{1}$ and $G_{2}$ can determine the $a$ and $b$ distances of the center of mass at the axes of the two decks, using the relations (1):

$\left\{\begin{array}{l}a=\frac{G_{2}}{G_{t}} \cdot L \\ b=\frac{G_{1}}{G_{t}} \cdot L\end{array}\right.$
Determining the height of the center of mass hg is done by placing the bus in an inclined position (Fig. 2) with the rear wheels on a weighing platform.

If the sum of the moments of all the forces in relation to the front wheel axle is obtained, the relation (2) where $G_{2}^{\prime}$ is the weight on the rear axle when the bus is inclined with an angle $\alpha$ and obtained by weighing:

$G_{2}^{\prime} \cdot L \cdot \cos \alpha-G_{t} \cdot a \cdot \cos \alpha-G_{t} \cdot\left(h_{g}-r\right) \cdot \sin \alpha=0$

Using the relationship (2) it is explicit from (2) the unknown $h_{g}$ (thus, expression 3 is obtained):

$h_{g}=\frac{G_{2}^{\prime}}{G_{t}} \cdot L \cdot \operatorname{ctg} \alpha-a \cdot \operatorname{ctg} \alpha+r$

Replacing in relation (3) $G_{t}=G_{2} \cdot L / a$, the final expression of the dimension $h_{g}(4)$ is obtained:

$h_{g}=a \cdot\left(\frac{G_{2}^{\prime}}{G_{2}}-1\right) \cdot \operatorname{ctg} \alpha+r$

Next, the stability of the bus will be studied, which means its ability not to overturn or slip during travel or in stationary.

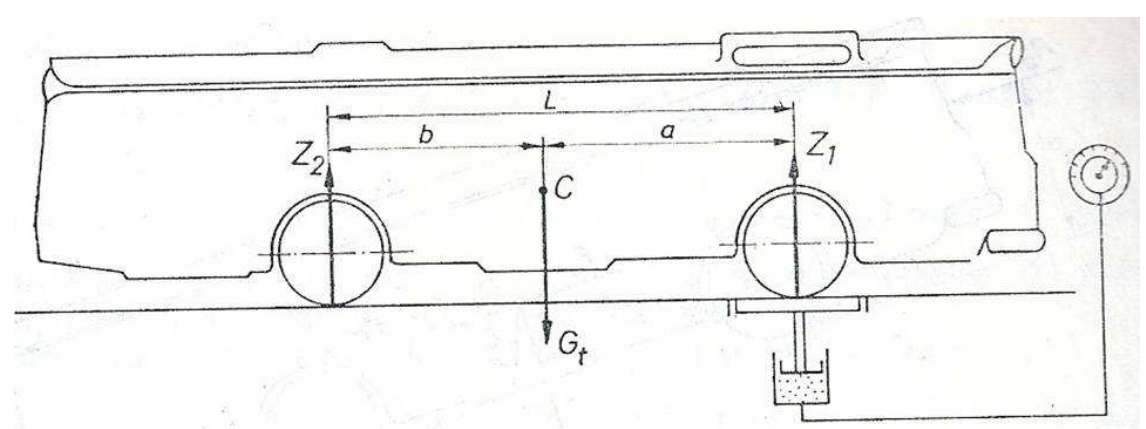

Fig. 1: Weighing the bus to determine bridging load

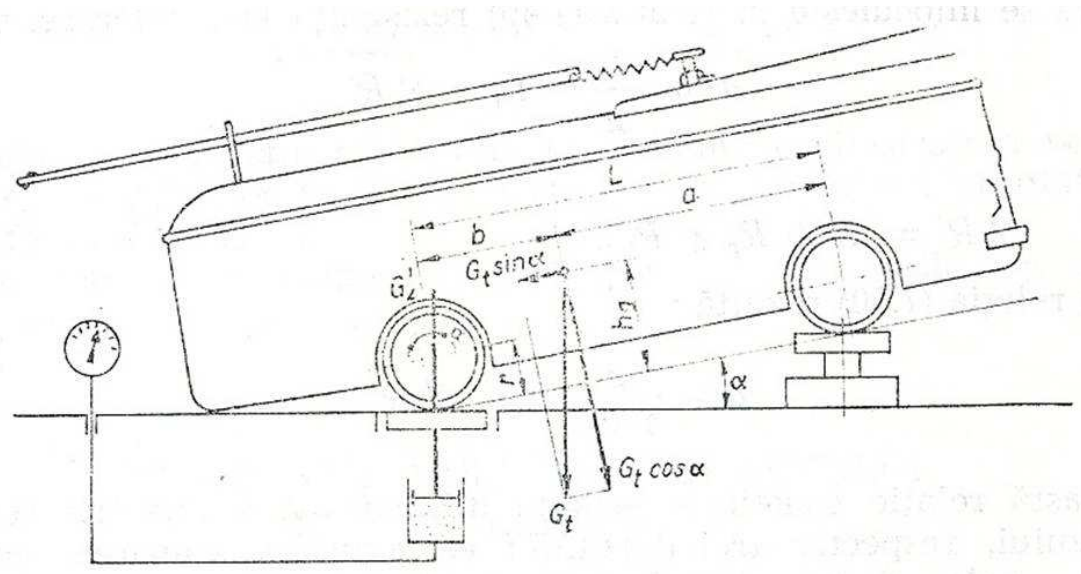

Fig. 2: Weighing the bus (trolleybus) to determine the height of the center of gravity 


\section{Longitudinal Stability of the Bus}

The longitudinal stability of the bus means its ability not to overturn around the rear or front wheels or to slip longitudinally when climbing a slope.

Figure 3 considers a bus that climbs a slope at a low and uniform speed. The movement can be considered because the overturning can occur in the case of large slopes.

Flipping around the straight line through the contact points B of the rear wheels with the road may occur when the tipping moment is greater than the moment of stability relative to the same point, i.e. (5):

$$
h_{g} \cdot G_{t} \cdot \sin \alpha+Z_{1} \cdot L>b \cdot G_{t} \cdot \cos \alpha
$$

If we consider the moment of the beginning of the overturning, when the point A deviates from the path, then the $Z_{1}$ reaction is canceled (no longer exists) and the relation (5) will be simplified by taking the form (6):

$$
h_{g} \cdot G_{t} \cdot \sin \alpha>b \cdot G_{t} \cdot \cos \alpha
$$

Thus, we can determine the value of the slope angle $\alpha$ at which the overturning (7) can occur, or the condition that the overturning of the bus does not occur around the wheels of the rear axle considering a maximum permissible slope $\alpha=45^{\circ}$, for which the tangent of the angle $\alpha$ take the unit value (8):

$$
\operatorname{tg} \alpha>\frac{b}{h_{g}}
$$

$$
\left\{\begin{array}{l}
h_{g}<\frac{b}{\operatorname{tg} \alpha} \\
\text { with } \alpha_{\max }=45[\mathrm{deg}] \Rightarrow \operatorname{tg} \alpha=1 \Rightarrow \\
\Rightarrow h_{g}<b
\end{array}\right.
$$

It is understood from the relationship (8) that the secret of the longitudinal stability of the bus (in a possible longitudinal overturning of the wheels of the rear axle) is that its design should be such that the center of gravity of the bus is as low as possible with possibly, hg being as small as possible.

\section{Transverse Stability of the Bus}

Loss of lateral stability may occur by turning or sideby-side swing due to the centrifugal force that occurs.

In the case of transverse tilt roads (Fig. 4), the centrifugal force $F_{c}$ and the bus weight are decomposed into parallel and perpendicular components on the road surface.

The overturning of the bus will occur when the sum of the moments of roll over the $\mathrm{O}_{2}$ point is greater than the sum of the moments of stability (opposing the roll) relative to the same point (9):

$$
\begin{aligned}
& Z_{d} \cdot B+\left(F_{c} \cdot \cos \beta-G_{t} \cdot \sin \beta\right) \cdot h_{g}> \\
& \left(F_{c} \cdot \sin \beta+G_{t} \cdot \cos \beta\right) \cdot \frac{B}{2}
\end{aligned}
$$

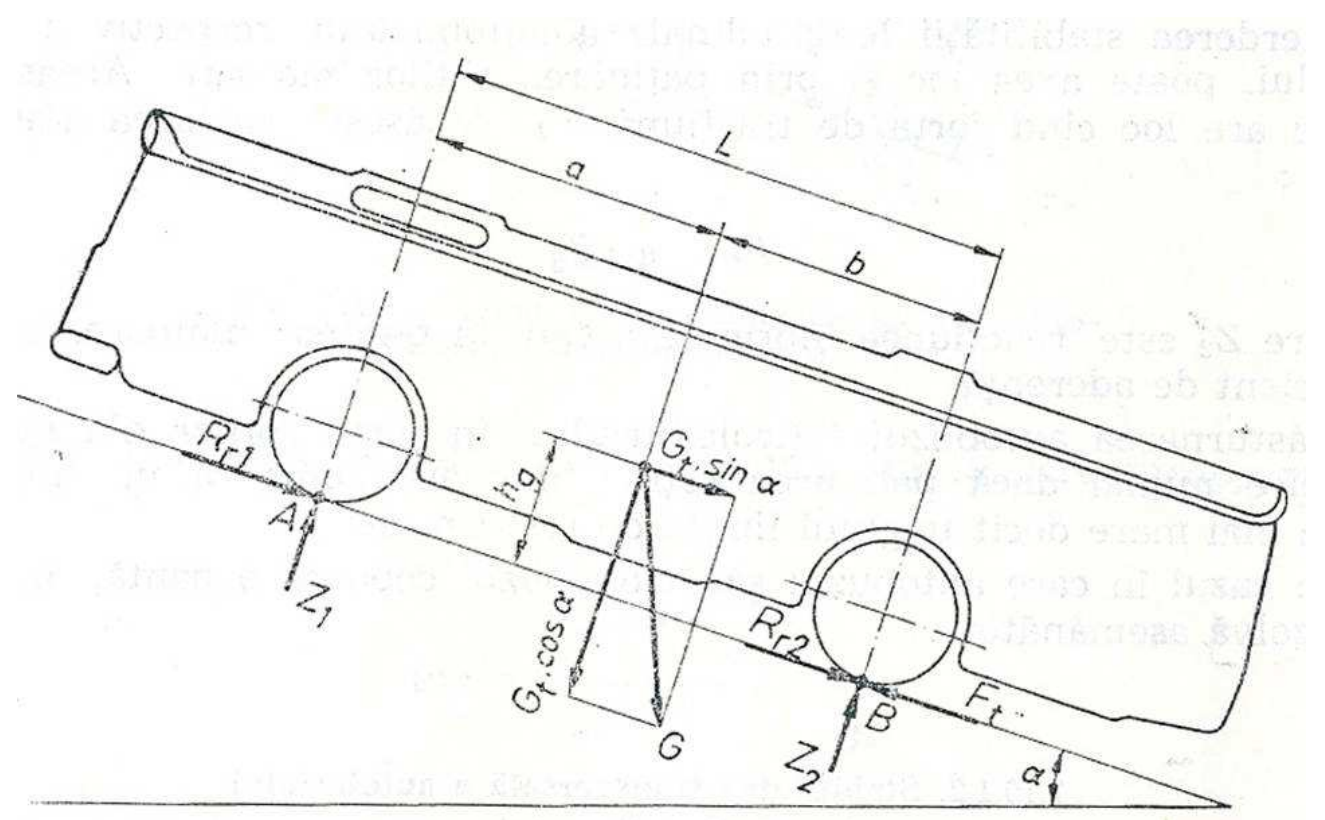

Fig. 3: The forces that act on the bus when climbing a slope 


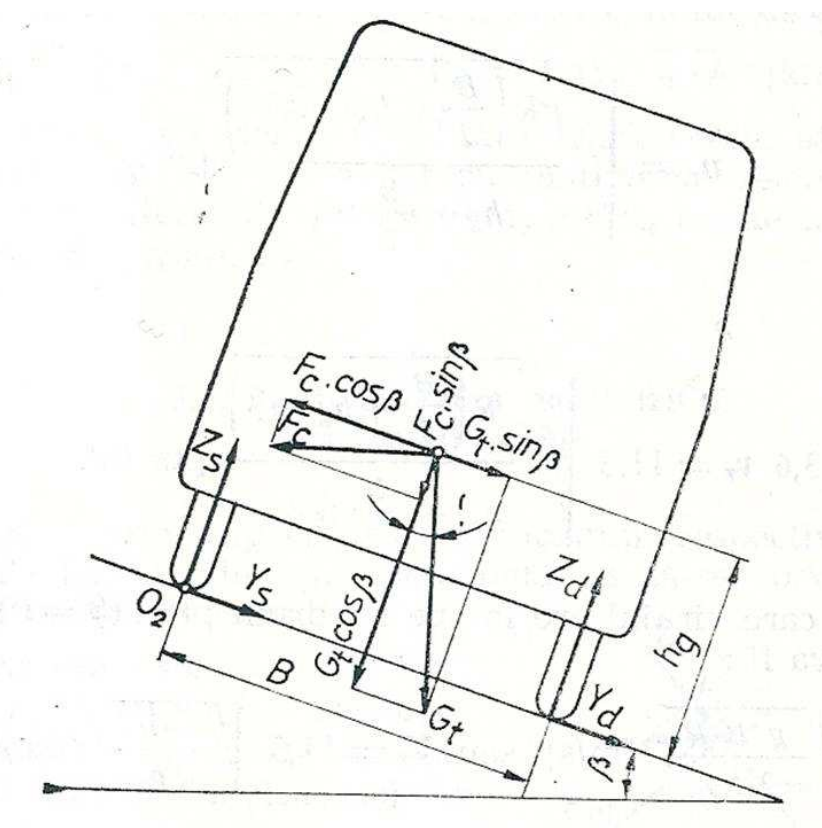

Fig. 4: Forces acting on a bus being in the curve

Because at the moment of the inversion $Z_{d}$ is canceled, the relation (9) changes accordingly and we obtain the expression (10) in which $\operatorname{tg} \beta$ must be limited in order not to overturn (in the expression 9 both terms were divided into costes and $Z_{d}$ was considered 0 , after which the value of $(\operatorname{tg} \beta)$ is explicit. The expression on the right is the limit value for which rollback begins:

$$
\operatorname{tg} \beta=\frac{h_{g} \cdot F_{c}-\frac{B}{2} \cdot G_{t}}{\frac{B}{2} \cdot F_{c}+h_{g} \cdot G_{t}}
$$

We know the centrifugal force that occurs during turn (11), where $\mathrm{v}$ is the bus speed in $\mathrm{m} / \mathrm{s}$ and $R$ is the radius of the turn in $m$ :

$F_{c}=\frac{G_{t}}{g} \cdot \frac{v^{2}}{R}$

Entering the value of the centrifugal force (11) in the relation (10) gives the expression (12), which shows the value of the angle at which the overturning begins:

$$
\operatorname{tg} \beta=\frac{\frac{h_{g} \cdot v^{2}}{g \cdot R}-\frac{B}{2}}{\frac{B \cdot v^{2}}{2 g \cdot R}+h_{g}}
$$

From here you can explain the value of the tipping speed at the turn with a radius $R$ on a tilt slope $\beta(13)$ :

$$
v_{r}=\sqrt{\frac{g \cdot R \cdot\left(\frac{B}{2}+h_{g} \cdot \operatorname{tg} \beta\right)}{h_{g}-\frac{B}{2} \cdot \operatorname{tg} \beta}}
$$

If the turn takes place on a flat road $(\beta=0)$, the tipping speed of the bus will be given by the particular relationship (14):

$v_{r}=\sqrt{\frac{g \cdot B \cdot R}{2 \cdot h_{g}}}$

In order to have cornering stability, the bus must have a distance $B$ between the wheels on the same deck as large as possible, the radius of rotation $R$ must be as large as possible (i.e., the swing should be as wide as possible) and the center height the hg weight must still be as small as possible.

The slip of the bus (Fig. 4) is possible when the relationship (15) occurs:

$$
F_{c} \cdot \cos \beta-G_{t} \cdot \sin \beta>Y_{s}+Y_{d}
$$

The maximum cross-reactive value $Y_{s}+Y_{d}$ is equal to the cross-link force (16):

$Y_{s}+Y_{d}=\varphi \cdot\left(F_{c} \cdot \sin \beta+G_{t} \cdot \cos \beta\right)$

By replacing the value (16) in relation (15) the expression (17) is obtained: 


$$
F_{c} \cdot \cos \beta-G_{t} \cdot \sin \beta>\varphi \cdot\left(F_{c} \cdot \sin \beta+G_{t} \cdot \cos \beta\right)
$$

The expression (17) explains the value of the angle $\beta$ at which the skew begins (18):

$$
\operatorname{tg} \beta=\frac{F_{c}-\varphi \cdot G_{t}}{\varphi \cdot F_{c}+G_{t}}
$$

If the centrifugal force $F_{c}$ is replaced with the relation (11), the expression (18) takes the form (19):

$$
\operatorname{tg} \beta=\frac{\frac{v^{2}}{R}-\varphi \cdot g}{\varphi \cdot \frac{v^{2}}{R}+g}
$$

From relation (19), the derating speed $v_{d}$ (20-21) results at the radius with a radius $R$ on a cross-pivoting path $\beta$ :

$$
\begin{aligned}
& v_{d}[\mathrm{~m} / \mathrm{s}]=\sqrt{\frac{R[\mathrm{~m}] \cdot \mathrm{g}\left[\mathrm{m} / \mathrm{s}^{2}\right] \cdot(\varphi+\operatorname{tg} \beta)}{1-\varphi \cdot \operatorname{tg} \beta}} \\
& V_{d}[\mathrm{~km} / \mathrm{h}]=11,28 \cdot \sqrt{\frac{R \cdot(\varphi+\operatorname{tg} \beta)}{1-\varphi \cdot \operatorname{tg} \beta}}
\end{aligned}
$$

When cornering on a flat road $(\beta=0)$, the skid speed limit will be given by the simplified relations (22-23):

$$
v_{d}[m / s]=\sqrt{g \cdot R \cdot \varphi}
$$

$V_{d}[\mathrm{~km} / \mathrm{h}]=11,28 \cdot \sqrt{R \cdot \varphi}$

It is recommended that loss of transverse stability occurs by skidding and not by overturning, for security reasons. For this reason, the skid speed should be less than the tipping speed $v_{d}$.

\section{Results and Discussion}

\section{Maniability of the Bus}

Maniability or maneuverability of a bus, is the ability of the bus to move in the direction controlled by the driver, or to maintain its rectilinear stroke.

It is considered a bussing turn (Fig. 5) with the parallel guides parallel to each other and inclined with the angle $\gamma$ to the longitudinal plane (in reality the steering wheels are not parallel in the turn but describe concentric circles with the center in $O$ ). With the traction on the rear wheels, each front wheel is driven by its axis with a thrust force $F$ parallel to the longitudinal axis of the bus. The two forces $F$ can decompose into a component in the plane of the wheel $F_{x}$ and one in a plane perpendicular to the plane of the wheel $F_{y}$. These components are given by the relationships (24):

$$
\left\{\begin{array}{l}
F_{x}=F \cdot \cos \gamma \\
F_{y}=F \cdot \sin \gamma
\end{array}\right.
$$

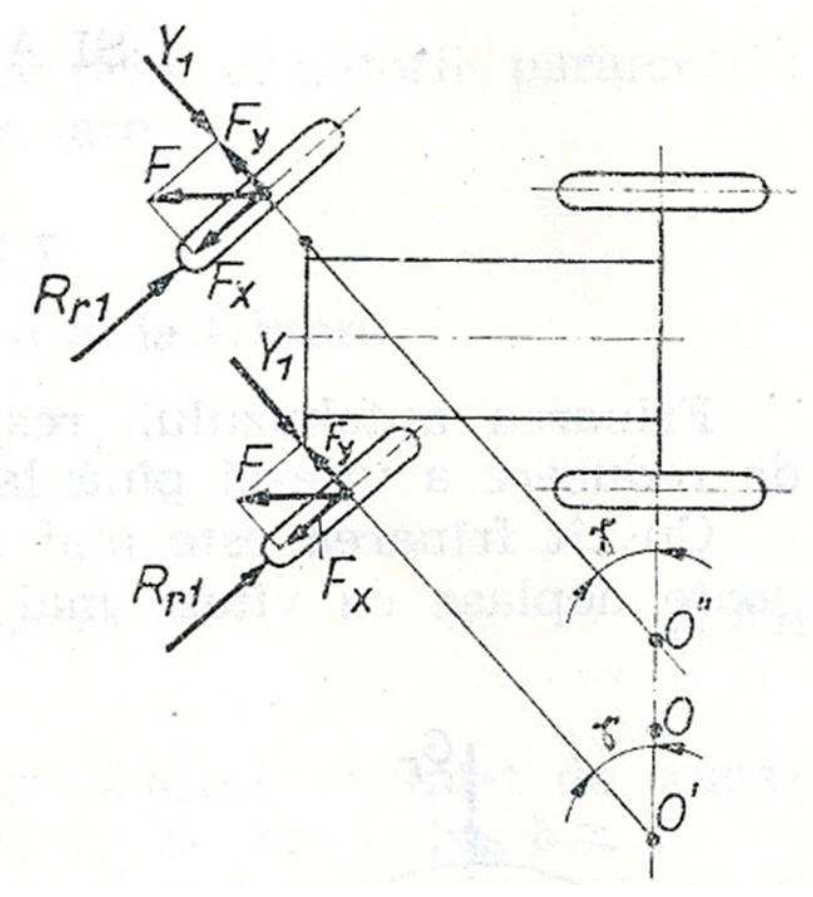

Fig. 5: Manageability of the bus when in a turn (in a curve) 
The rolling resistance $R_{r 1}$, which opposes the movement of a wheel, must be defeated by the force $F_{x}$. The condition of rolling the wheel $(25)$ to be produced is:

$$
F_{x}=F \cdot \cos \gamma \geq R_{r 1}
$$

The $F_{y}$ component seeks to produce the transverse sliding of the wheel, but is prevented by the $Y_{1}$ transverse grip. The condition that the transverse sliding does not occur is (26):

$$
F_{y}=F \cdot \sin \gamma \leq Y_{1}
$$

The condition of the maneuverability of the turn buss (30) (i.e., the turn is properly performed by the inclination of the steering wheels) is obtained by eliminating the force $F$ between the relations (25) and (26). From the relations (24) the expression (27) is obtained:

$$
F_{y}=F_{x} \cdot \operatorname{tg} \gamma \Rightarrow F_{x}=\frac{F_{y}}{\operatorname{tg} \gamma}
$$

The expression (27) together with relation (25) generates the relation (28):

$$
\frac{F_{y}}{\operatorname{tg} \gamma} \geq R_{r 1} \Rightarrow F_{y} \geq R_{r 1} \cdot \operatorname{tg} \gamma
$$

Taking account of relations (28) and simultaneously, the expression (29) can be written:

$$
R_{r 1} \cdot \operatorname{tg} \gamma \leq F_{y} \leq Y_{1}
$$

From (29) we stop only the expression (30) which represents the maneuverability condition and which can be processed in the form (31) if the rolling resistance $\left(R_{r 1}=f . Z_{r 1}\right)$ and the transverse adhesion $\left(Y_{1}=\varphi . Z_{r 1}\right)$, where $Z r 1$ is the normal path reaction at one of the steering wheels, $\varphi$ is the coefficient of rolling resistance and $f$ is the coefficient of adhesion:

$$
\begin{aligned}
& R_{r 1} \cdot \operatorname{tg} \gamma \leq Y_{1} \\
& f \cdot \operatorname{tg} \gamma \leq \varphi
\end{aligned}
$$

When traveling on a dry road with hard cover, the maneuverability condition is automatically satisfied because the adhesion coefficient $\mathrm{f}$ is several times lower than the rolling resistance coefficient $\varphi$ and $\operatorname{tg} \gamma$ is less than 1 because the angle $\gamma$ does not exceed 40 [deg].

On slippery roads (poles, water, snow...) it is often possible that the maneuverability condition (8) is not satisfied if the bus is to move in a straight line and when it has the inclined wheels to turn, from the cause of slippage on wheels. This phenomenon is not desirable, as it is an inexperienced driver a great danger of producing road accidents.

\section{Study of Bus Braking}

Braking the bus is the process of reducing its speed to a certain value or to stopping.

The more secure, the more intense, the faster and the braked, the more the bus can move safely at higher speeds. The braking capacity therefore depends on the possibility of increasing the average speed of the bus and also the safety of the bus and its passengers depends on it.

Each bus is constructively provided with a braking system that acts on each wheel, giving rise to braking moments on each wheel, moments that seek to immobilize each wheel individually.

The brake torque $M_{f}$ (Fig. 6) is produced by friction of a drum or disk 1 (solidarity with the wheel marked with 2) with some brakes with the fixed part of the deck (carter). The braking torque is opposed to the rotation of the wheel and seeks to immobilize it.

During the braking, the bus moves only under inertial forces, consuming the kinetic energy produced and accumulating at acceleration.

Under the action of the $M_{f}$ braking torque in the contact area of the wheel with the road, the soil reactivity $F_{f}$ is directed in the opposite direction to the bus movement.

When braking the brake apart from the braking force, it contributes to slowing speed and resistance to advancing.

According to the principle of dynamic balance in the bus braking, we can write the relation (32), where $F_{i}$ is the inertia force of the bus:

$F_{i}=F_{f}+R_{r} \pm R_{p}+R_{a}$

Replacing $F_{i}$ and all forward resistances with their already known expressions, obtain the expression (33):

$\frac{G_{t}}{g} \cdot \delta \cdot a_{f}=F_{f}+G_{t} \cdot f \cdot \cos \alpha \pm G_{t} \cdot p+\frac{K \cdot A \cdot V^{2}}{13}$

Taking into account that both rolling and air resistance to bus travel at speeds of less than $100[\mathrm{~km} / \mathrm{h}]$ are small compared to the braking force, both can be neglected so that the relationship (33) will take the simplified aspect (34).

$$
\frac{G_{t}}{g} \cdot \delta \cdot a_{f}=F_{f} \pm G_{t} \cdot p
$$

The braking capacity of a bus (like any other vehicle) is characterized by the following parameters: deceleration, braking area and braking time (eventually stopping). 


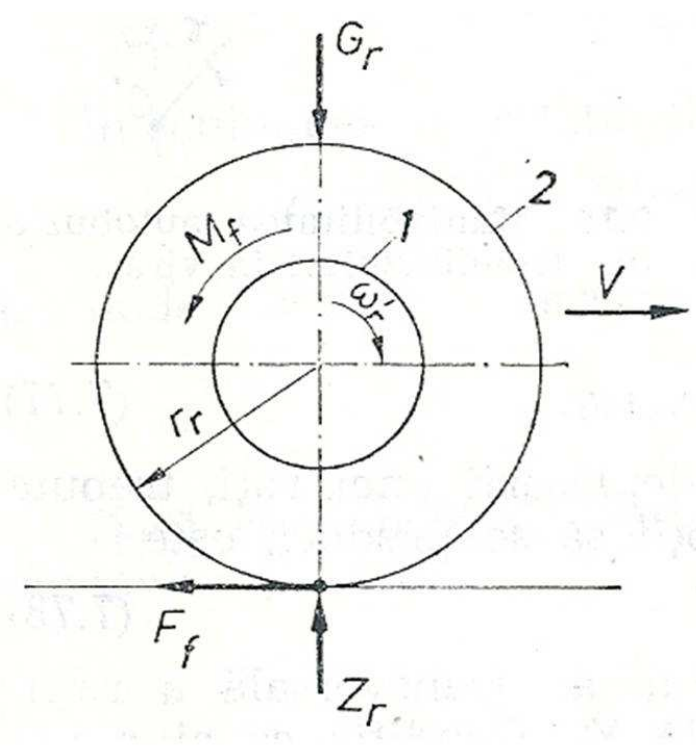

Fig. 6: The forces and moments acting on a braked wheel

\section{Determination of Braking Deceleration}

The expression of deceleration results from the relationship (35):

$a_{f}=\frac{g}{\delta \cdot G_{t}} \cdot\left(F_{f} \pm G_{t} \cdot p\right)$

If braking is considered to be with the engine off the transmission, the coefficient of mass influence in rotation can be taken $\delta \cong 1$. For a road with a certain slope $p$, the deceleration obtained will be maximum when the braking force has the maximum value (36):

$$
\left(a_{f}\right)_{\max }=\frac{g}{G_{t}} \cdot\left(F_{f \max } \pm G_{t} \cdot p\right)
$$

The maximum braking force is limited by grip (37), where $G_{\text {adf }}$ is the adherent brake bus weight:

$$
F_{f \max }=G_{a d f} \cdot \varphi
$$

In the case of a bus (trolley) having all the braked wheels when traveling on a slope, the relation (37) is written in the form (38):

$$
F_{f \max }=G_{t} \cdot \varphi \cdot \cos \alpha
$$

By replacing the expression (38) in the relation (36) we obtain the relation (39) which defines the deceleration of the deceleration of the bus on any slope road:

$$
\left(a_{f}\right)_{\max }=g \cdot(\varphi \cdot \cos \alpha \pm p)
$$

If the bus travels on a straight road at the moment of braking, the deceleration of the brake deceleration changes accordingly, simplifying it to form (40), being proportional to the gravitational acceleration $g$ and the coefficient of rolling resistance $\varphi$ :

$$
\left(a_{f}\right)_{\max }=g \cdot \varphi
$$

\section{Determination of the Braking Area}

During braking, according to the kinetic energy theorem, the variation of the kinetic energy is equal to the mechanical work (braking force) corresponding to the braking space.

Considering that the braking takes place with the off-set motor, according to the kinetic energy theorem, the relation (41), where $\mathrm{m}$ is the mass of the bus, $v_{1}$ is the speed at the start of braking in $\mathrm{m} / \mathrm{s}, v_{2}$ is the end braking speed in $\mathrm{m} / \mathrm{s}$ and $s_{f}$ represents the braking area in $m$ :

$\frac{m \cdot\left(v_{1}^{2}-v_{2}^{2}\right)}{2}=\left(F_{f}+R_{r} \pm R_{p}+R_{a}\right) \cdot s_{f}$

If the bus runs at speeds of less than $100 \mathrm{~km} / \mathrm{h}$ when braking, the influences of the rolling resistance $R_{r}$ and the air resistance $R_{a}$ can be neglected, so that the relation (41) takes the simplified form (42-43) where the mass of the bus was substituted with $G_{t} / g$ and all elements are measured in SI:

$\frac{m \cdot\left(v_{1}^{2}-v_{2}^{2}\right)}{2}=\left(F_{f} \pm R_{p}\right) \cdot s_{f}$ 


$$
s_{f}=\frac{G_{t} \cdot\left(v_{1}^{2}-v_{2}^{2}\right)}{2 \cdot g \cdot\left(F_{f} \pm R_{p}\right)}
$$

However, if we want to introduce the two speeds in $\mathrm{km} / \mathrm{h}$, the relation (43) takes the form (44) where $V_{1}$ and $V_{2}$ are introduced in $\mathrm{km} / \mathrm{h}$ :

$$
s_{f}=\frac{G_{t} \cdot\left(V_{1}^{2}-V_{2}^{2}\right)}{26 \cdot g \cdot\left(F_{f} \pm R_{p}\right)}
$$

The minimum braking distance corresponding to a certain slope shall be obtained when the braking force has a maximum value (45):

$$
s_{f \text { min }}=\frac{G_{t} \cdot\left(V_{1}^{2}-V_{2}^{2}\right)}{26 \cdot g \cdot\left(F_{f \max } \pm R_{p}\right)}
$$

For a bus that has all braked wheels, replacing $F_{\text {fmax }}$ from relation (38) and $R_{p}=p \cdot G_{t}$, the relation (46) or braking to stop (when $\left.V_{2}=0\right),(47)$ :

$$
\begin{aligned}
& s_{f \text { min }}=\frac{\left(V_{1}^{2}-V_{2}^{2}\right)}{26 \cdot g \cdot(\varphi \cdot \cos \alpha \pm p)} \\
& s_{f \text { min }}=\frac{V_{1}^{2}}{26 \cdot g \cdot(\varphi \cdot \cos \alpha \pm p)}
\end{aligned}
$$

If the bus travels on a straight path, the expression (46) takes shape (48) and the relation (47) takes the simplified form (49), where (48) is the minimum braking space on a straight road, the minimum stop on a straight road, the bus:

$$
s_{f \min }=\frac{\left(V_{1}^{2}-V_{2}^{2}\right)}{26 \cdot g \cdot \varphi}
$$

$$
s_{f \min }=\frac{V_{1}^{2}}{26 \cdot g \cdot \varphi}
$$

\section{Determination of Braking Time}

If the bus is considered to have an even slowed down motion during the braking period and if its deceleration is equal to $\left(a_{f}\right) \max$, then the minimum braking time will be given by the relation (50), where all elements are given in the international system ( $v_{1}$ and $v_{2}$ being entered in $\mathrm{m} / \mathrm{s}$ ), so the time will also result in $\mathrm{s}$.

$t_{\min }=\frac{v_{1}-v_{2}}{\left(a_{f}\right)_{\max }}=\frac{v_{1}-v_{2}}{g \cdot(\varphi \cdot \cos \alpha \pm p)}$

In the case of braking to stop $\left(v_{2}=0\right)$, the minimum braking time will be given by the simplified relationship (51):

$t_{\text {min }}=\frac{v_{1}}{\left(a_{f}\right)_{\text {max }}}=\frac{v_{1}}{g \cdot(\varphi \cdot \cos \alpha \pm p)}$

In reality, however, both the minimum braking distance and the minimum braking time have values higher than those calculated with the theoretically indicated relationships, because during the total braking time, the time needed to react to the bus driver and the time required to enter the action of the bus braking system.

\section{Observation}

The previously determined formulas have all been deduced when all brakes instantaneously come into action with their full braking force.

Figure 7 shows the variation of deceleration over time as well as the braking time intervals.

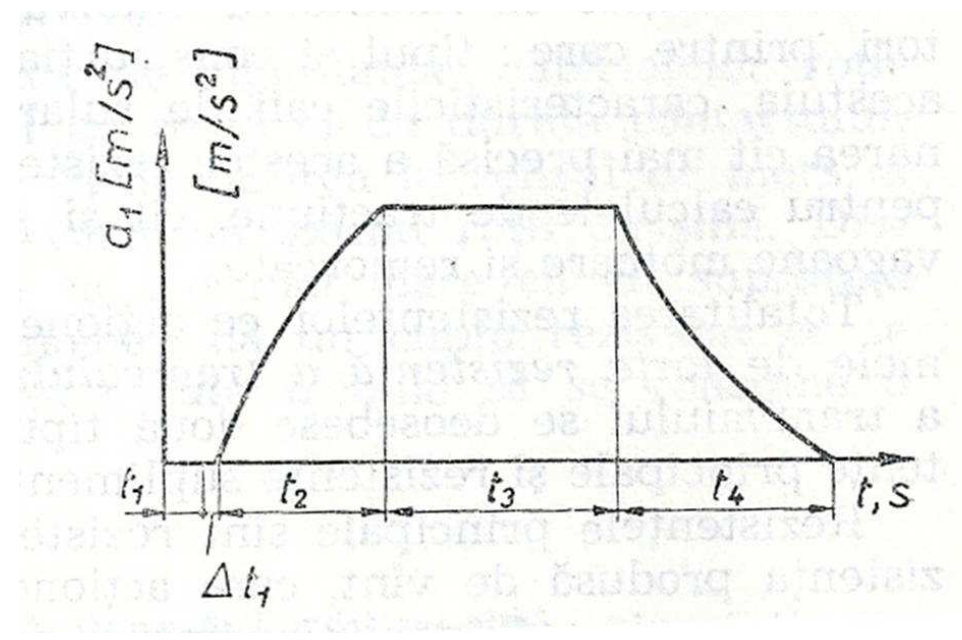

Fig. 7: Variation of deceleration in function of the time 
Time $t_{1}$ is the response time of the driver and is equal to the time elapsed since the brake application was sensed until the actual start of braking. This time ranges from 0.4 to $1 \mathrm{~s}$, depending on both the physiological state of the driver and his skill and experience.

The deceleration delay time $\Delta t_{1}$ depends on the operating time of the pedal brake transmission mechanism and is due to the joints in the joints, the fluids of the fluids through the pipes... ranging from 0.2 to $0,5 \mathrm{~s}$.

Time $t_{2}$ is the time elapsed from the moment when the braking force starts to reach its maximum value. It varies between 0.1 and $1 \mathrm{sec}$, depending on the type of braking control.

Time $t_{3}$ is the actual braking time at normal parameters, from the bus speed from the beginning of the braking $v_{1}$ to the braking end $v_{2}$ (which may be 0 in the event of braking until stopping).

Time $t_{4}$ is the time elapsed between canceling the pedal and canceling the braking force. It is between 0.2 and $2 \mathrm{sec}$ but does not directly influence the previous braking area (from actual braking), but only indirectly when braking has only slowed the bus and a new slowdown is needed (a new brake), or even stopping it, its influence being only on the next possible braking.

The additional space $s_{f 0}$ traveled by the bus due to delays specific to the braking is given by the relation (52) with the speed $v_{1}$ given in $\mathrm{m} / \mathrm{s}$ and is expressed by the relation (53) if the speed $V_{1}$ is introduced in $\mathrm{km} / \mathrm{h}$ :

$s_{f 0}=v_{1} \cdot\left(t_{1}+\Delta t_{1}+t_{2}\right)$

$s_{f 0}=\frac{V_{1}}{3,6} \cdot\left(t_{1}+\Delta t_{1}+t_{2}\right)$

Obviously, braking and using the engine brake is accomplished in a much shorter time and realizes increased braking security when necessary, being more efficient as the experience, skill and physiological state of the bus driver are better. Gradual or direct passage from the top to the bottom of the transaxle helps to effectively brake by the engine brake, usually passing to the third (from a higher stage) and eventually, then, even in step a two, if necessary. At the slope, especially at the descent, at high starting speeds for braking and when the road is slippery, the use of the engine brake is imperative.

\section{Conclusion}

The present paper aims to present the study of the dynamics of the vehicles, with particularization on the buses. Here are the main elements of the bus dynamics, taking into account all the elements that influence the dynamic operation of a bus, in general and in particular situations, with emphasis on the main systems and elements that act on the actual, dynamic, on a normal path or on an inclined with an alpha angle path. The paper presents the third part of the bus dynamics.

\section{Acknowledgement}

This text was acknowledged and appreciated by Dr. Veturia CHIROIU Honorific member of Technical Sciences Academy of Romania (ASTR) PhD supervisor in Mechanical Engineering.

\section{Author's Contributions}

All the authors contributed equally to prepare, develop and carry out this manuscript.

\section{Ethics}

This article is original and contains unpublished material. Authors declare that are not ethical issues and no conflict of interest that may arise after the publication of this manuscript.

\section{References}

Antonescu, P., 2000. Mechanisms and Handlers. 1st Edn., Printech Publishing House, Bucharest.

Antonescu, P. and F. Petrescu, 1985. Analytical method of synthesis of cam mechanism and flat stick. Proceedings of the 4th International Symposium on Mechanism Theory and Practice, (TPM' 85), Bucharest.

Antonescu, P. and F. Petrescu, 1989. Contributions to cinetoelastodynamic analysis of distribution mechanisms. Bucharest.

Antonescu, P., M. Oprean and F. Petrescu, 1985a. Contributions to the synthesis of oscillating cam mechanism and oscillating flat stick. Proceedings of the 4th International Symposium on Theory and Practice of Mechanisms, (TPM' 85), Bucharest.

Antonescu, P., M. Oprean and F. Petrescu, 1985b. At the projection of the oscillante cams, there are mechanisms and distribution variables. Proceedings of the 5th Conference for Engines, Automobiles, Tractors and Agricultural Machines, I-Engines and Automobiles, (AMA' 85), Brasov.

Antonescu, P., M. Oprean and F. Petrescu, 1986. Projection of the profile of the rotating camshaft acting on the oscillating plate with disengagement. Proceedings of the 3rd National Computer Assisted Designing Symposium in Mechanisms and Machine Bodies, (MMB’ 86), Brasov.

Antonescu, P., M. Oprean and F. Petrescu, 1987. Dynamic analysis of the cam distribution mechanisms. Proceedings of the 7th National Symposium of Industrial Robots and Spatial Mechanisms, (RSM' 87), Bucharest. 
Antonescu, P., M. Oprean and F. Petrescu, 1988. Analytical synthesis of Kurz profile, rotating flat cam. Machine Build. Rev. Bucharest.

Antonescu, P., F. Petrescu and O. Antonescu, 1994. Contributions to the synthesis of the rotating cam mechanism and the tip of the balancing tip. Brasov.

Antonescu, P., F. Petrescu and D. Antonescu, 1997. Geometrical synthesis of the rotary cam and balance tappet mechanism. Bucharest.

Antonescu, P., F. Petrescu and O. Antonescu, 2000a. Contributions to the synthesis of the rotary disc-cam profile. Proceedings of the 8th International Conference on Theory of Machines and Mechanisms, (TMM' 00), Liberec, Czech Republic, pp: 51-56.

Antonescu, P., F. Petrescu and O. Antonescu, $2000 \mathrm{~b}$. Synthesis of the rotary cam profile with balance follower. Proceedings of the 8th Symposium on Mechanisms and Mechanical Transmissions, (MMT'000), Timişoara, pp: 39-44.

Antonescu, P., F. Petrescu and O. Antonescu, 2001. Contributions to the synthesis of mechanisms with rotary disc-cam. Proceedings of the 8th IFToMM International Symposium on Theory of Machines and Mechanisms, (TMM' 01), Bucharest, ROMANIA, pp: 31-36.

Aversa, R., R.V. Petrescu, A. Apicella and F.I.T. Petrescu, 2017a. Nano-diamond hybrid materials for structural biomedical application. Am. J. Biochem. Biotechnol., 13: 34-41. DOI: 10.3844/ajbbsp.2017.34.41

Aversa, R., R.V. Petrescu, B. Akash, R.B. Bucinell and J.M. Corchado et al., 2017b. Kinematics and forces to a new model forging manipulator. Am. J. Applied Sci., 14: 60-80. DOI: 10.3844/ajassp.2017.60.80

Aversa, R., R.V. Petrescu, A. Apicella, F.I.T. Petrescu and J.K. Calautit et al., 2017c. Something about the $\mathrm{V}$ engines design. Am. J. Applied Sci., 14: 34-52. DOI: 10.3844/ajassp.2017.34.52

Aversa, R., D. Parcesepe, R.V. Petrescu, F. Berto and G. Chen et al., 2017d. Processability of bulk metallic glasses. Am. J. Applied Sci., 14: 294-301. DOI: 10.3844/ajassp.2017.294.301

Aversa, R., R.V. Petrescu, A. Apicella and F.I.T. Petrescu, 2017e. Modern transportation and photovoltaic energy for urban ecotourism. Transylvanian Rev. Admin. Sci., 13: 5-20. DOI: 10.24193/tras.SI2017.1

Aversa, R., F.I.T. Petrescu, R.V. Petrescu and A. Apicella, 2016a. Biomimetic FEA bone modeling for customized hybrid biological prostheses development. Am. J. Applied Sci., 13: 1060-1067. DOI: 10.3844/ajassp.2016.1060.1067

Aversa, R., D. Parcesepe, R.V. Petrescu, G. Chen and F.I.T. Petrescu et al., 2016b. Glassy amorphous metal injection molded induced morphological defects. Am. J. Applied Sci., 13: 1476-1482. DOI: 10.3844 ajassp.2016.1476.1482
Aversa, R., R.V. Petrescu, F.I.T. Petrescu and A. Apicella, 2016c. Smart-factory: Optimization and process control of composite centrifuged pipes. Am. J. Applied Sci., 13: 1330-1341. DOI: 10.3844/ajassp.2016.1330.1341

Aversa, R., F. Tamburrino, R.V. Petrescu, F.I.T. Petrescu and M. Artur et al., 2016d. Biomechanically inspired shape memory effect machines driven by muscle like acting NiTi alloys. Am. J. Applied Sci., 13: 1264-1271. DOI: 10.3844/ajassp.2016.1264.1271

Cao, W., H. Ding, Z. Bin and C. Ziming, 2013. New structural representation and digital-analysis platform for symmetrical parallel mechanisms. Int. J. Adv. Robot. Syst. DOI: 10.5772/56380

Comănescu, A., D. Comănescu, I. Dugăeşescu and A. Boureci, 2010. The Basics of Modeling Mechanisms. 1st Edn., Politehnica Press Publishing House, Bucharest, ISBN-10: 978-606-515-115-4, pp: 274.

Dong, H., N. Giakoumidis, N. Figueroa and N. Mavridis, 2013. Approaching behaviour monitor and vibration indication in developing a General Moving Object Alarm System (GMOAS). Int. J. Adv. Robot. Sys. DOI: $10.5772 / 56586$

De Melo, L.F., R.A., S.F. Rosário and J.M., Rosário, 2012. Mobile robot navigation modelling, control and applications. Int. Rev. Modell. Simulat., 5: 1059-1068.

Frăţilă, G., M. Frăţilă and S. Samoilă, 2011. Automobiles, Construction, Exploitation, Reparation. 10th Edn., EDP, Bucharest, ISBN-10: 978-973-30-2857-4, pp: 480 .

Garcia, E., M.A. Jimenez, P.G. De Santos and M. Armada, 2007. The evolution of robotics research. IEEE Robot. Autom. Magaz., 14: 90-103. DOI: 10.1109/MRA.2007.339608

Garcia-Murillo, M., J. Gallardo-Alvarado and E. Castillo-Castaneda, 2013. Finding the generalized forces of a series-parallel manipulator. IJARS. DOI: $10.5772 / 53824$

He, B., Z. Wang, Q. Li, H. Xie and R. Shen, 2013. An analytic method for the kinematics and dynamics of a multiple-backbone continuum robot. IJARS. DOI: $10.5772 / 54051$

Lee, B.J., 2013. Geometrical derivation of differential kinematics to calibrate model parameters of flexible manipulator. Int. J. Adv. Robot. Sys. DOI: $10.5772 / 55592$

Lin, W., B. Li, X. Yang and D. Zhang, 2013. Modelling and control of inverse dynamics for a 5-DOF parallel kinematic polishing machine. Int. J. Adv. Robot. Sys. DOI: 10.5772/54966

Liu, H., W. Zhou, X. Lai and S. Zhu, 2013. An efficient inverse kinematic algorithm for a PUMA560-structured robot manipulator. IJARS. DOI: $10.5772 / 56403$ 
Mirsayar, M.M., V.A. Joneidi, R.V. Petrescu, F.I.T. Petrescu and F. Berto, 2017. Extended MTSN criterion for fracture analysis of soda lime glass. Eng. Fracture Mechan., 178: 50-59. DOI: $10.1016 /$ j.engfracmech.2017.04.018

Padula, F. and V. Perdereau, 2013. An on-line path planner for industrial manipulators. Int. J. Adv. Robot. Sys. DOI: 10.5772/55063

Pelecudi, C., 1967. The Basics of Mechanism Analysis. 1st Edn., Publishing House: Academy of the People's Republic of Romania.

Perumaal, S. and N. Jawahar, 2013. Automated trajectory planner of industrial robot for pick-and-place task. IJARS. DOI: $10.5772 / 53940$

Petrescu, F. and R. Petrescu, 1995a. Contributions to optimization of the polynomial motion laws of the stick from the internal combustion engine distribution mechanism. Bucharest.

Petrescu, F. and R. Petrescu, 1995b. Contributions to the synthesis of internal combustion engine distribution mechanisms. Bucharest.

Petrescu, F. and R. Petrescu, 1997a. Dynamics of cam mechanisms (exemplified on the classic distribution mechanism). Bucharest.

Petrescu, F. and R. Petrescu, 1997b. Contributions to the synthesis of the distribution mechanisms of internal combustion engines with Cartesian coordinate method. Bucharest.

Petrescu, F. and R. Petrescu, 1997c. Contributions to maximizing polynomial laws for the active stroke of the distribution mechanism from internal combustion engines. Bucharest.

Petrescu, F. and R. Petrescu, 2000a. Synthesis of distribution mechanisms by the rectangular (cartesian) coordinate method. University of Craiova, Craiova.

Petrescu, F. and R. Petrescu, 2000b. The design (synthesis) of cams using the polar coordinate method (the triangle method). University of Craiova, Craiova.

Petrescu, F. and R. Petrescu, 2002a. Motion laws for cams. Proceedings of the 7th National Symposium with International Participation Computer Assisted Design, (PAC' 02), Braşov, pp: 321-326.

Petrescu, F. and R. Petrescu, 2002b. Camshaft dynamics elements. Proceedings of the 7th National Symposium with International Participation Computer Assisted Design, (PAC' 02), Braşov, pp: 327-332.

Petrescu, F. and R. Petrescu, 2003. Some elements regarding the improvement of the engine design. Proceedings of the 8th National Symposium, Descriptive Geometry, Technical Graphics and Design, (GTD’03), Braşov, pp: 353-358.

Petrescu, F. and R. Petrescu, 2005a. The cam design for a better efficiency. Proceedings of the International Conference on Engineering Graphics and Design, (EGD’05), Bucharest, pp: 245-248.
Petrescu, F. and R. Petrescu, 2005b. Contributions at the dynamics of cams. Proceedings of the 9th IFToMM International Symposium on Theory of Machines and Mechanisms, (TMM' 05), Bucharest, Romania, pp: 123-128.

Petrescu, F. and R. Petrescu, 2005c. Determining the dynamic efficiency of cams. Proceedings of the 9th IFToMM International Symposium on Theory of Machines and Mechanisms, (TMM' 05), Bucharest, Romania, pp: 129-134.

Petrescu, F. and R. Petrescu, 2005d. An original internal combustion engine. Proceedings of the 9th IFToMM International Symposium on Theory of Machines and Mechanisms, (TMM' 05), Bucharest, Romania, pp: 135-140.

Petrescu, F. and R. Petrescu, 2005e. Determining the mechanical efficiency of Otto engine's mechanism. Proceedings of the 9th IFToMM International Symposium on Theory of Machines and Mechanisms, (TMM' 05), Bucharest, Romania, pp: 141-146.

Petrescu, F.I. and R.V. Petrescu, 2013. Cinematics of the 3R dyad. Engevista, 15: 118-124.

Petrescu, F.I. and R.V. Petrescu, 2012a. Kinematics of the planar quadrilateral mechanism. Engevista, 14: 345-348.

Petrescu, F.I. and R.V. Petrescu, 2012b. MecatronicaSisteme Seriale si Paralele. 1st Edn., Create Space Publisher, USA, ISBN-10: 978-1-4750-6613-5, pp: 128.

Petrescu, F.I. and R.V. Petrescu, 2011. Mechanical Systems, Serial and Parallel-Course (in Romanian). 1st Edn., LULU Publisher, London, UK, ISBN-10: 978-1-4466-0039-9, pp: 124.

Petrescu, F.I. and R.V. Petrescu, 2016a. Parallel moving mechanical systems kinematics, Engevista, 18: 455-491.

Petrescu, F.I. and R.V. Petrescu, 2016b. Direct and inverse kinematics to the Anthropomorphic Robots, Engevista, 18: 109-124.

Petrescu, F. and R. Petrescu, 2016c. An otto engine dynamic model. IJM\&P, 7: 038-048.

Petrescu, F.I. and R.V. Petrescu, 2016d. Otto motor dynamics, GEINTEC, 6: 3392-3406.

Petrescu, F.I. and R.V. Petrescu, 2016e. Dynamic cinematic to a structure 2R. Geintec, 6: 3143-3154.

Petrescu, F.I., B. Grecu, A. Comanescu and R.V. Petrescu, 2009. Some mechanical design elements. Proceeding of the International Conference on Computational Mechanics and Virtual Engineering, (MEC' 09), Braşov, pp: 520-525.

Petrescu, R.V., R. Aversa, A. Apicella, M.M. Mirsayar and F.I.T. Petrescu, 2016a. About the gear efficiency to a simple planetary train. Am. J. Applied Sci., 13: 1428-1436. 
Petrescu, R.V., R. Aversa, A. Apicella, S. Li and G. Chen et al., 2016b. Something about electron dimension. Am. J. Applied Sci., 13: 1272-1276.

Petrescu, F.I.T., A. Apicella, R. Aversa, R.V. Petrescu and J.K. Calautit et al., 2016c. Something about the mechanical moment of inertia. Am. J. Applied Sci., 13: $1085-1090$.

Petrescu, R.V., R. Aversa, A. Apicella, F. Berto and S. Li et al., 2016d. Ecosphere protection through green energy. Am. J. Applied Sci., 13: 1027-1032.

Petrescu, F.I.T., A. Apicella, R.V. Petrescu, S.P. Kozaitis and R.B. Bucinell et al., 2016e. Environmental protection through nuclear energy. Am. J. Applied Sci., 13: 941-946.

Petrescu, F.I.T. and J.K. Calautit, 2016a. About nano fusion and dynamic fusion. Am. J. Applied Sci., 13: 261-266.

Petrescu, F.I.T. and J.K. Calautit, 2016b. About the light dimensions. Am. J. Applied Sci., 13: 321-325.

Petrescu, R.V., R. Aversa, B. Akash, R. Bucinell and J. Corchado et al., 2017a. Modern propulsions for aerospace-a review. J. Aircraft Spacecraft Technol., 1: 1-8. DOI: $10.3844 /$ jastsp.2017.1.8

Petrescu, R.V., R. Aversa, B. Akash, R. Bucinell and J. Corchado et al., 2017b. Modern propulsions for aerospace-part II. J. Aircraft Spacecraft Technol., 1: 9-17. DOI: 10.3844/jastsp.2017.9.17

Petrescu, R.V., R. Aversa, B. Akash, R. Bucinell and J. Corchado et al., 2017c. History of aviation-a short review. J. Aircraft Spacecraft Technol., 1: 30-49.

DOI: 10.3844 jastsp.2017.30.49

Petrescu, R.V., R. Aversa, B. Akash, R. Bucinell and J. Corchado et al., 2017d. Lockheed martin-a short review. J. Aircraft Spacecraft Technol., 1: 50-68. DOI: 10.3844 /jastsp.2017.50.68

Petrescu, R.V., R. Aversa, B. Akash, J. Corchado and F. Berto et al., 2017e. Our universe. J. Aircraft Spacecraft Technol., 1: 69-79. DOI: 10.3844/jastsp.2017.69.79

Petrescu, R.V., R. Aversa, B. Akash, J. Corchado and F. Berto et al., 2017f. What is a UFO? J. Aircraft Spacecraft Technol., 1: 80-90. DOI: 10.3844 /jastsp.2017.80.90

Petrescu, R.V., R. Aversa, B. Akash, J. Corchado and F. Berto et al., 2017g. About bell helicopter FCX001 concept aircraft-a short review. J. Aircraft Spacecraft Technol., 1: 91-96. DOI: 10.3844 /jastsp.2017.91.96

Petrescu, R.V., R. Aversa, B. Akash, J. Corchado and F. Berto et al., 2017h. Home at airbus. J. Aircraft Spacecraft Technol., 1: 97-118. DOI: $10.3844 /$ jastsp.2017.97.118

Petrescu, R.V., R. Aversa, B. Akash, J. Corchado and F. Berto et al., 2017i. Airlander. J. Aircraft Spacecraft Technol., 1: 119-148. DOI: $10.3844 /$ jastsp.2017.119.148
Petrescu, R.V., R. Aversa, B. Akash, J. Corchado and F. Berto et al., 2017j. When boeing is dreaming-a review. J. Aircraft Spacecraft Technol., 1: 149-161. DOI: 10.3844 /jastsp.2017.149.161

Petrescu, R.V., R. Aversa, B. Akash, J. Corchado and F. Berto et al., 2017k. About Northrop Grumman. J. Aircraft Spacecraft Technol., 1: 162-185. DOI: $10.3844 /$ jastsp.2017.162.185

Petrescu, R.V., R. Aversa, B. Akash, J. Corchado and F. Berto et al., 20171. Some special aircraft. J. Aircraft Spacecraft Technol., 1: 186-203. DOI: $10.3844 /$ jastsp.2017.186.203

Petrescu, R.V., R. Aversa, B. Akash, J. Corchado and F. Berto et al., 2017m. About helicopters. J. Aircraft Spacecraft Technol., 1: 204-223.

DOI: $10.3844 /$ jastsp.2017.204.223

Petrescu, R.V., R. Aversa, B. Akash, F. Berto and A. Apicella et al., 2017n. The modern flight. J. Aircraft Spacecraft Technol., 1: 224-233. DOI: $10.3844 /$ jastsp.2017.224.233

Petrescu, R.V., R. Aversa, B. Akash, F. Berto and A. Apicella et al., 2017o. Sustainable energy for aerospace vessels. J. Aircraft Spacecraft Technol., 1: 234-240. DOI: 10.3844/jastsp.2017.234.240

Petrescu, R.V., R. Aversa, B. Akash, F. Berto and A. Apicella et al., 2017p. Unmanned helicopters. J. Aircraft Spacecraft Technol., 1: 241-248. DOI: $10.3844 /$ jastsp.2017.241.248

Petrescu, R.V., R. Aversa, B. Akash, F. Berto and A. Apicella et al., 2017q. Project HARP. J. Aircraft Spacecraft Technol., 1: 249-257. DOI: 10.3844 /jastsp.2017.249.257

Petrescu, R.V., R. Aversa, B. Akash, F. Berto and A. Apicella et al., 2017r. Presentation of romanian engineers who contributed to the development of global aeronautics-part I. J. Aircraft Spacecraft Technol., 1: 258-271. DOI: 10.3844 /jastsp.2017.258.271

Petrescu, R.V., R. Aversa, B. Akash, F. Berto and A. Apicella et al., 2017s. A first-class ticket to the planet mars, please. J. Aircraft Spacecraft Technol., 1: 272-281. DOI: 10.3844/jastsp.2017.272.281

Petrescu, R.V., R. Aversa, B. Akash, F. Berto and A. Apicella et al., 2017t. Forces of a 3R robot. J. Mechatron. Robot., 1: 1-14. DOI: $10.3844 /$ jmrsp.2017.1.14

Petrescu, R.V., R. Aversa, B. Akash, F. Berto and A. Apicella et al., 2017u. Direct geometry and cinematic to the MP-3R systems. J. Mechatron. Robot., 1: 15-23. DOI: 10.3844/jmrsp.2017.15.23

Petrescu, R.V., R. Aversa, B. Akash, F. Berto and A. Apicella et al., 2017v. Dynamic elements at MP3R. J. Mechatron. Robot., 1: 24-37.

DOI: $10.3844 / j m r s p .2017 .24 .37$ 
Petrescu, R.V., R. Aversa, B. Akash, F. Berto and A. Apicella et al., 2017w. Geometry and direct kinematics to MP3R with $4 \times 4$ operators. J. Mechatron. Robot., 1: 38-46. DOI: 10.3844/jmrsp.2017.38.46

Petrescu, R.V., R. Aversa, A. Apicella, M.M. Mirsayar and S. Kozaitis et al., 2017x. Current stage in the field of mechanisms with gears and rods. J. Mechatron. Robot., 1: 47-57. DOI: 10.3844/jmrsp.2017.47.57

Petrescu, R.V., R. Aversa, A. Apicella, M.M. Mirsayar and S. Kozaitis et al., 2017y. Geometry and inverse kinematic at the MP3R mobile systems. J. Mechatron. Robot., 1: 58-65. DOI: 10.3844/jmrsp.2017.58.65

Petrescu, R.V., R. Aversa, A. Apicella, M.M. Mirsayar and S. Kozaitis et al., 2017z. Synthesis of optimal trajectories with functions control at the level of the kinematic drive couplings. J. Mechatron. Robot., 1: 66-74. DOI: 10.3844/jmrsp.2017.66.74

Petrescu, R.V., R. Aversa, A. Apicella, M.M. Mirsayar and S. Kozaitis et al., 2017aa. The inverse kinematics of the plane system 2-3 in a mechatronic MP2R system, by a trigonometric method. J. Mechatron. Robot., 1: 75-87. DOI: 10.3844/jmrsp.2017.75.87

Petrescu, R.V., R. Aversa, A. Apicella, M.M. Mirsayar and S. Kozaitis et al., 2017ab. Serial, anthropomorphic, spatial, mechatronic systems can be studied more simply in a plan. J. Mechatron. Robot., 1: 88-97. DOI: 10.3844/jmrsp.2017.88.97

Petrescu, R.V., R. Aversa, A. Apicella, M.M. Mirsayar and S. Kozaitis et al., 2017ac. Analysis and synthesis of mechanisms with bars and gears used in robots and manipulators. J. Mechatron. Robot., 1: 98-108. DOI: 10.3844/jmrsp.2017.98.108
Petrescu, R.V., R. Aversa, A. Apicella, M.M. Mirsayar and S. Kozaitis et al., 2017ad. Speeds and accelerations in direct kinematics to the MP3R systems. J. Mechatron. Robot., 1: 109-117. DOI: $10.3844 /$ jmrsp.2017.109.117

Petrescu, R.V., R. Aversa, A. Apicella, M.M. Mirsayar and S. Kozaitis et al., 2017ae. Geometry and determining the positions of a plan transporter manipulator. J. Mechatron. Robot., 1: 118-126. DOI: $10.3844 /$ jmrsp.2017.118.126

Reddy, P., K.V. Shihabudheen and J. Jacob, 2012. Precise non linear modeling of flexible link flexible joint manipulator. IReMoS, 5: 1368-1374.

Tabaković, S., M. Zeljković, R. Gatalo and A. Živković, 2013. Program suite for conceptual designing of parallel mechanism-based robots and machine tools. Int. J. Adv. Robot Sys. DOI: 10.5772/56633

Tang, X., D. Sun and Z. Shao, 2013. The structure and dimensional design of a reconfigurable PKM. IJARS. DOI: $10.5772 / 54696$

Tong, G., J. Gu and W. Xie, 2013. Virtual entity-based rapid prototype for design and simulation of humanoid robots. Int. J. Adv. Robot. Sys. DOI: $10.5772 / 55936$

Wang, K., M. Luo, T. Mei, J. Zhao and Y. Cao, 2013. Dynamics analysis of a three-DOF planar serialparallel mechanism for active dynamic balancing with respect to a given trajectory. Int. J. Adv. Robotic Sys. DOI: 10.5772/54201

Wen, S., J. Zhu, X. Li, A. Rad and X. Chen, 2012. End-point contact force control with quantitative feedback theory for mobile robots. IJARS. DOI: $10.5772 / 53742$ 